\title{
Research on Competence Model of Operation and Maintenance Talents in Intelligent Manufacturing System
}

\author{
Jiqing Cao \\ Suzhou Industrial Park Institute of Service Outsourcing, Suzhou, China \\ george.cao@siso.edu.cn
}

Keywords: intelligent manufacturing, operation and maintenance, productive services, competency model

\begin{abstract}
With the development of intelligent manufacturing, the demand for operation and maintenance talents of intelligent manufacturing system will be more prominent. In response to the country's training policy for productive services and their talents, this paper studies the establishment process of the competency model of operation and maintenance talents in intelligent manufacturing system based on the DevOps and the model framework of CMMI. From the three ability latitudes of the breadth, depth and size, this paper introduces the information encoding process, system architecture, capability maturity level, ability indicators and weights, establishes the three-level competency ability dictionary from ability domain, working process to working task. Finally, the paper summarizes the areas where the model needs further improvement and predicts the application value of the model in the training and operation of intelligent manufacturing system in Higher Vocational Education and the post qualification system of enterprises.
\end{abstract}

\section{Introduction}

In 2015, the Chinese State Council issued a series of documents such as “China made 2025” and "Guidance on Accelerating the Development of Productive Service Industry to Promote the Adjustment and Upgrading of Industrial Structure”, which had a far-reaching impact on the transformation of China's manufacturing industry and put forward new requirements for the needs of enterprise talents. In the process of promoting intelligent manufacturing, the boundaries of different industries will be removed slowly, and the industrial chain will be rebuilt to change the ability of the staff in the manufacturing field [1]. According to McKinsey survey, by 2020, China will need 140 million high skilled talents. If vocational education cannot adapt to the development of advanced manufacturing industry and cultivate more skilled talents, China will face a gap of about 20 million high skilled talents by that time [2]. Among the highly skilled talents, the productive service posts include industrial design, logistics, supply chain management, operation and maintenance (O\&M) service, energy conservation and environmental protection services, etc. Most of these posts belong to the productive service industry, which are most suitable for the cultivation of higher vocational colleges.

This paper is focused on the O\&M talents in the intelligent manufacturing system. Referring to the modeling method of Competency Model and the Capability Maturity Model Integration (CMMI), this paper setups the model framework and the capacity model of the O\&M talents and provides reference and guidance for the training of high skilled talents in the $O \& M$ of the intelligent manufacturing system, as well as the training and assessment of the enterprise O\&M staff.

\section{Modeling Process}

\subsection{Competency Model and CMMI}

The Competency Model describes all the abilities and qualities that a job needs in a competent enterprise. The Competency Model is widely applied in the field of human resources, such as employee recruitment, training, evaluation and promotion. The abilities in Competency Model can 
be divided into three categories as knowledge, skills and professionalism. Through the guidance of these three types of abilities, we can correctly guide employees to achieve the post capabilities that enterprises need. The CMMI model is an international standard for assessing the maturity of an organization's ability. It is divided into five maturity levels in the framework. Different maturity levels include a number of ability processes, and different process domains include a number of capacity items. The organization can refer to the CMMI model for targeted improvement and evaluation.

The model of Operation and Maintenance Talent Capability Model in Intelligent Manufacturing System, hereinafter referred to as TCM, comprehensively uses the modeling methods of CM and CMMI, such as "Core Competence Derivation”, “Ability Dictionary”, "Best Practice”, "Behavioral Event Interview and Information Coding", and designs and establishes the model with the five major steps as "Identify the Modeling Object", "Core Competence Deduction", "System Architecture Design”, “Capability Dictionary Establishment” and "Model Revision and Validation” [3].

\subsection{Determining the Modeling Object}

In traditional manufacturing enterprises, the departments of design, production, quality assurance, production deployment, equipment O\&M, system O\&M are mutually independent, and even O\&M are divided into different departments such as production equipment $\mathrm{O} \& \mathrm{M}$, production information system O\&M and O\&M of office management system. According to the DevOps (Development and Operations), the barriers between these teams must be cut through, because each team may delay production cycles and bring potential risks [4]. The O\&M posts in the intelligent manufacturing enterprise are the role of a comprehensive technical management position. In the study of this model, we integrate the above typical positions into one category, which is named as the O\&M post of the intelligent manufacturing system.

\subsection{Core Ability Derivation}

On the basis of the investigation of a number of intelligent manufacturing enterprises and the job holders of their target positions, we use the post responsibility derivation method, which is to deduce what typical working process and job must be mastered by the job holder of the target post in order to perform his own job responsibilities. And then through the analysis of the process and work tasks of the job, the core ability system of the target post is derived [5]. According to the theory of Competency Model, these abilities can be analyzed and sorted from three aspects of breadth, depth and granularity.

Considering the breadth of ability, the O\&M talents of the intelligent manufacturing system need the following four core abilities. We define four Ability Domains in the TCM, as shown in Figure 1.

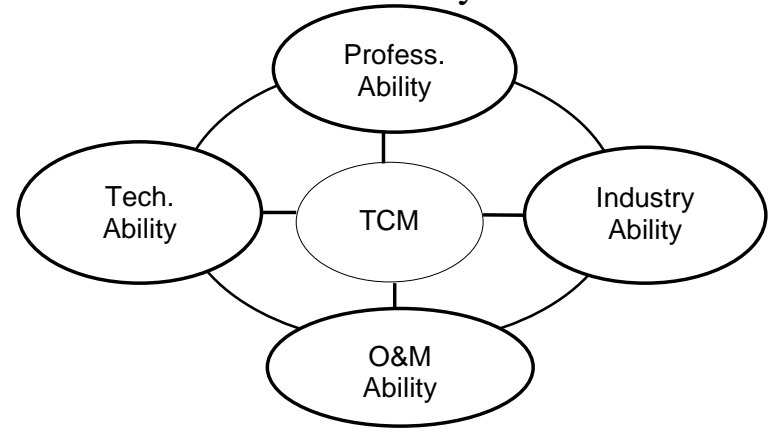

Fig. 1. Core Ability Domain of O\&M Talents

\subsubsection{Professionalism Ability}

According to the iceberg theory of CM, the ability of professionalism ability can be divided into four categories as social consciousness, self- concept, trait and motivation. Except for the social consciousness, self-concept and trait suitable for the industry and the post, the O\&M talents of the intelligent manufacturing system should have especially the ability to be able to learn and acquire new knowledge quickly, and the motivations to coordinate and cooperate with people to deal with 
the qualities of the complex tasks.

\subsubsection{Technology Ability}

To change the default, adjust the template as follows. The O\&M talents are required to be familiar with the mechanical, electronic, automation, information, artificial intelligence and comprehensive English ability related to intelligent manufacturing, to understand the product description and technical documents related to the intelligent manufacturing system, and to be familiar with the key technologies and implementation of intelligent factories and intelligent logistics, etc. These are the basic abilities of O\&M in intelligent manufacturing systems.

\subsubsection{Industry Ability}

As a new generation of industrial revolution, intelligent manufacturing requires broad professional abilities such as business knowledge of the typical manufacturing industry, the management and international standard knowledge of enterprise management, production management, quality management, and information security management system, etc.

\subsubsection{O\&M Ability}

With the deep application of high and new technology such as industrial robot, digital manufacturing and cloud platform, etc., the system O\&M talents should not only be able to master the technical skills of O\&M in the intelligent manufacturing system, but also work closely with technicians, equipment engineers and software engineers to ensure the normal operation of the system. They need to have the O\&M abilities of IT infrastructure, automation systems, information systems and artificial intelligence systems, system security, and process management and tools, etc.

\subsection{Architecture Design}

Referring to the system architecture of the CMMI model, the abilities of the TCM are divided into three levels from the vertical, the first level is the Ability Domain, the second level is the Working Process or Post Knowledge, and the third level is the Work Task or Knowledge Points. Each maturity level has four Ability Domains, each of which contains a number of typical Work Processes. Each typical Work Process contains a number of typical Work Tasks (see Figure 2).

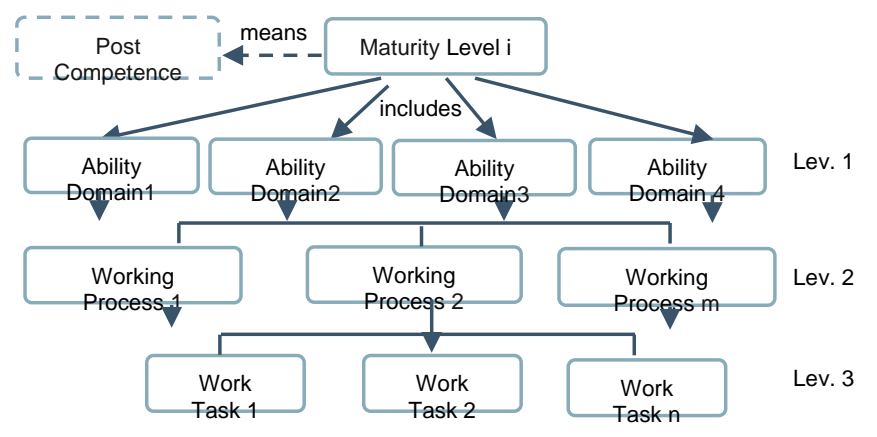

Fig. 2. TCM System Architecture

If all Work Tasks and Knowledge Points under a typical Working Process have been mastered, it shows that the O\&M talents have mastered the corresponding ability of the typical Working Process. If all the typical Work Processes and Post Knowledge under a Ability Domain have been mastered, it shows that the O\&M talents have reached the corresponding ability requirements of the Ability Domain. If the four Ability Domains have reached the corresponding requirements, it shows that the O\&M talents have the ability required by the level of maturity of the post, and we can confirm they qualified for the qualification of the post. [6]

\subsection{Ability Dictionary Establishment}

After the establishment of the model system architecture, we fill in the corresponding ability level of the TCM in the form of the two levels of the" Work Process and Work Task”, which are obtained in the research of the intelligent manufacturing enterprises and establish the Ability Dictionary of the 
TCM.

The Ability Dictionary is a detailed description of the model, and there is an inherent logical relationship between the knowledge, skills and professionalism [7]. Among them, knowledge is the basis of talents' executive skills. Without good knowledge base, the degree of professional skills will be greatly reduced. If the talents only have professional knowledge and skills but no corresponding professionalism, the talents will not be consistent with the requirements of the enterprise, and they will be difficult to achieve the work goal in the work.

\subsubsection{The establishment of the Working Process}

From the perspective of model application, we refer to the design of the Competency Model Ability Dictionary, which stipulates that each Ability Domain contains several Working Processes and Job Knowledges. Each Working Process further includes a number of Work Tasks and Knowledge Points. The number of ability items at the two levels is generally required to be controlled at about 5 10 (see m, $\mathrm{n}$ in Figure 2) [8]. Table I show all the Level-2 ability items contained in "System O\&M technology capability" of the Ability Domain.

TABLE I. Ability Items of O\&M Ability Domain

\begin{tabular}{l|l}
\hline SN & Description of Work Process and Post Knowledge \\
\hline 1 & $\begin{array}{l}\text { Understanding the O\&M skills of hardware as equipment and } \\
\text { machine }\end{array}$ \\
\hline 2 & Familiarity with the ITIL O\&M system \\
\hline 3 & Familiarity with the concept and practice of DevOps \\
\hline 5 & $\begin{array}{l}\text { Familiarity with the O\&M ability model of intelligent } \\
\text { manufacturing system }\end{array}$ \\
\hline 6 & $\begin{array}{l}\text { Mastering the O\&M skills of the IT infrastructure } \\
\text { system the O\&M skills of the common industrial software }\end{array}$ \\
\hline 7 & Mastering the O\&M skills of common O\&M software and tools \\
\hline 8 & Mastering the O\&M skills of system and network security \\
\hline
\end{tabular}

In the above table, there are three different ability levels as Mastery, Familiarity and Understanding, different degrees of the position requires mastering the different levels of the ability items. The difference between Mastery, Familiarity and Understanding lies in the application of ability. Familiarity representatives a higher degree of understanding of a certain ability. Mastery requires not only familiarity but also proficiency in application and operation, and Understanding means it is enough the talent knows the knowledge point in theory.

\subsubsection{Establishment of Work Task}

Each typical Work Process in the model can be decomposed into several typical tasks and smaller professional knowledge points. Work Tasks correspond to the Ability Indicators in talents assessment techniques, which must be measurable and directive. Table II is the typical Work Task and Knowledge Point contained in the Level-2 ability items of "Mastering the O\&M skills of the common industrial software system”. 
TABLE II. Typical Tasks of Level-2 O\&M Ability

\begin{tabular}{l|l}
\hline S/N & Description of Work Task and Knowledge Point \\
\hline 1 & $\begin{array}{l}\text { Familiarity with the knowledge of the three integrated } \\
\text { direction of intelligent manufacturing system }\end{array}$ \\
\hline 2 & $\begin{array}{l}\text { Familiarity with the technology and architecture of the } \\
\text { industrial Cloud Service Platform }\end{array}$ \\
\hline 3 & $\begin{array}{l}\text { Familiarity with ESB(Enterprise Service Bus) architecture } \\
\text { and its application }\end{array}$ \\
\hline 5 & Mastering the O\&M skills of the ERP system \\
\hline 6 & Mastering the O\&M skills of the MES system \\
\hline 8 & $\begin{array}{l}\text { Mastering the O\&M skills of PLC and other control layer } \\
\text { Service Platform }\end{array}$ \\
\hline
\end{tabular}

The typical working processes and tasks that are identified generally summarize the requirements of the capacity of the O\&M talents of the intelligent manufacturing system. On this basis, the teaching design can be carried out according to the law of vocational education. Usually a typical work process describes a learning field, and a typical task reflects a learning ability point included in the course, and all the Level-1 to Level-3 ability items of the model constitute the course system for the target position [9]. Therefore, this model can provide guidance for intelligent manufacturing system O\&M talents to continuously learn, master and improve their knowledge and skills.

\subsubsection{Determination of Weight}

After the establishment of the Ability Dictionary, an important task is to determine the weight of the "Ability Domain", "Work Process" and "Work Task" in the model at their respective levels. The weight of certain ability has a direct impact on the future of the model-based Specialty Construction, Curriculum Setting, and the degree to which the stakeholders attach importance to it. It has an important teaching-oriented role [10]. In the process of weight establishment, we determine the empirical weights corresponding to each level in accordance with the Expert Judgment Method with the industry experts and the enterprise engineers. It should be pointed out that this weight represents the ratio of the hours of the corresponding ability rather than the importance. Table III is the weight of four "Ability Domains” in the TCM.

TABLE III. Weight of the Four Ability Domains

\begin{tabular}{l|c|c}
\hline S/N & Ability Domain & Weight \\
\hline 1 & Professionalism Ability & $5 \%$ \\
\hline 2 & Technology Ability & $25 \%$ \\
\hline 3 & Industry Ability & $10 \%$ \\
\hline 4 & O\&M Ability & $60 \%$ \\
\hline
\end{tabular}

It can be seen that, for the intelligent manufacturing system, the Professionalism Ability is the most important for the O\&M talents in the intelligent manufacturing system, so the corresponding time weight of the Domain also should account for most of the teaching hours. While the proportion of comprehensive professionalism is relatively low, but as far as the Competency Model is concerned, it has the highest degree of competence for the talents. It cannot be trained through a single sermon, and it must be combined with practice to affect the students synthetically.

\subsubsection{Correction and Verification}

With the deep application of high In the validation phase of the model, we transform the TCM 
Ability Dictionary into a series of list of ability items, and use structured questionnaire to verify the model of the representative post of the intelligent manufacturing enterprise. According to the relevance of the ability items in the questionnaire and their true work, these operators assess the ability items at each level to confirm the frequency of their use of certain ability: (1) it is necessary, (2) useful but not necessary, (3) no need. Through the analysis of the survey data, it is possible to determine whether the Ability Dictionary of the TCM is consistent with the understanding of the most target positions.

After the completion of the verification work, the TCM covers most of the abilities required for the successful completion of the target position. The modeling work of the TCM has been completed on the teaching objectives of Specialty Construction, Curriculum Setting and Employment Assessment.

\section{Summary}

The establishment of this model can solve two problems in the training of higher vocational talents. One is the problem of teaching entrance, that is, through the Ability Dictionary of TCM, we can easily set up the curriculum of the O\&M Specialty of the intelligent manufacturing system through "the Course Development Method Based on the Working Process and the Work Task". The other is the export problem, that is, based on this model, we can develop an evaluation system for the O\&M talents, evaluate the students trained in colleges and universities, and judge whether they have reached the qualifications of the relevant positions. This model can also be further applied to the industry. Based on this model, it can establish the qualification of posts in the enterprise, and provide reference and guidance for the recruitment, training and promotion of the target posts in the enterprise.

In the modeling process of TCM, we also encountered some challenges. For example, for manufacturing enterprises of different types and industries, their definition of the Ability Index and Weight of the same post is often different, while the model needs a comprehensive and unified Ability Index and Weight as a teaching purpose, so how to make the model reflect the ability requirements of the post of the most corresponding target category and industry is a big challenge. In addition, another challenge is how to describe the Ability Domain be "measurable and directive" in the model, so further research and improvement are needed.

\section{Acknowledgment}

In this paper, the research was sponsored by "2017 Jiangsu Provincial University of Philosophy and Social Science Research Fund Project” (Project No. 2017SJB1953).

\section{References}

[1] Peng Qibo. Research on Talent Cultivation of the Characteristic Specialty in Vocational Colleges under the Background of Intelligent Manufacturing [J]. Journal of Ningbo Polytechnic, 2017(1).

[2] Zhang Ye, Li He, Zhuang Wen. Research on the innovation of talents training mode in Colleges and Universities under the background of industry 4 [J]. Economic \& Trade, 2017(9).

[3] Qin Yangyong. Five step method for the design of Competence model [M]. Xiamen: Lujiang Publishing House, 2009:42-45.

[4] Zhang Jun, Zeng Youxin. Innovation and application of DevOps in enterprise informatization strategy [J]. Kexue yu Xinxihua, 2017(1).

[5] Xie Haihong. Research on the Informatization Application of the Competence Model in Electric Power Enterprises [J]. Human Resource Development of China, 2013(7).

[6] Cao Jiqing. Research on competency maturity model of software outsourcing talents [J]. Career 
Horizon, 2011(9).

[7] Qin Yangyong. Five step method for the design of Competence model [M]. Xiamen: Lujiang Publishing House, 2009:151-160.

[8] Liu Kui, Cai Shenggang. Talents evaluation technique [M]. Dalian: Dongbei University of Finance and Economics press,2008:111-119.

[9] Zhao Zhiqun, Guide for curriculum development of work integrated learning in Vocational Education [M]. Beijing: Tsinghua University press, 2010:39-45.

[10] Liu Kui, Cai Shenggang. Talents evaluation technique [M]. Dalian: Dongbei University of Finance and Economics press, 2008: 177-184. 